\title{
Modeling Commuter Preferences for the Proposed Bus Rapid Transit in Dar-es-Salaam
}

\author{
Alphonse Nkurunziza, Mark Zuidgeest, Mark Brussel, \\ Martin Van Maarseveen \\ University of Twente, The Netherlands
}

\begin{abstract}
The paper analyzes individual commuter preferences towards the proposed bus rapid transit (BRT) system in Dar-es-Salaam, Tanzania. The objective of the survey was to identify how commuters perceive and value the proposed BRT service quality attributes. A stated preference survey of potential users of the proposed BRT was administered to 684 commuters who traveled to the central business district (CBD) on a regular basis. To this end, a special pictorial score card was developed that was suited for the local context and needed to capture the preferences of the commuter respondents. The BRT attributes considered for study are travel time, travel fare, and comfort. The stated choice data were analyzed using a binary logit model. The findings reveal, in order of importance, that comfort is the most valued attribute compared to travel time and travel fare, respectively.
\end{abstract}

\section{Introduction}

In the city of Dar-es-Salaam, Tanzania, as elsewhere in developing countries, concerns over urban growth and its transport implications are becoming more important in both the national and local political agendas. This is particularly true in the city where increasingly new peripheral developments have resulted to increased 
congestion and placed stress upon the local transport networks and the urban environment (World Bank and OECD. 2003). Dar-es-Salaam is one of the fastestgrowing cities in Sub-Saharan Africa, with an estimated urban population of almost 4 million inhabitants in 2010 and annual population growth rate of more than 4 percent per annum (JICA 2007). The city is characterized by a high proportion of informal development and poverty where nearly 70 percent of its population lives in informal settlements (World Bank 2002). Most people cannot afford a private car, and around 75 percent of trips in Dar-es-Salaam are made by public transport and walking (Olvera et al. 2003; Nkurunziza et al. 2012).

Like many other rapidly-growing cities in Sub-Saharan Africa, Dar-es-Salaam has not escaped from the impacts of poor public transport services: inefficiency, poor quality of service, and lack of safety for commuters. The main factors leading to these include rapid expansion of the city, which has far outpaced the capacity to provide basic infrastructure and services; the poor state of a majority of the buses; untrained bus drivers and conductors who are driven by the pursuit of daily revenue targets payable to bus owners; non-adherence to traffic rules and regulations; and lack of an organized public transport system (Kanyama et al. 2004; Nkurunziza et al. 2012). The city public transport service is mainly dominated by small busesDaladalas-with capacities ranging from 16 to 35 passengers. The actual fare level of a Daladala is between 250 and 350 Tshs (Tanzania Shillings; 1 US\$= approx. 1,200 Tshs, at time of survey), independent of the travel distance. The current public transport system has great difficulty in coping with the demographic and spatial growth of the city and in meeting the basic needs of its inhabitants (Sohail et al. 2004). Access to affordable and good quality public transport services is critical for the urban population, as a lack thereof leads to economic, social, and physical isolation (Department for International Development 1999), especially low-income communities located in the city outskirts with inadequate access to public transport and other basic urban facilities (Hine 2003; Olvera et al. 2003).

In response to the public transport challenges in Dar-es Salaam, an urban development strategy was designed and proposed to introduce a bus rapid transit system (BRT) for the entire city (ITDP 2005). BRT has emerged as an economical transit alternative with significant potential for developing countries (Wright 2002). Today, the BRT concept is becoming increasingly implemented by cities looking for cost-effective transit solutions. The proposed BRT system, branded Dar-es-Salaam Rapid Transit (DART), will operate on specially-designated infrastructure and is planned to replace the current inefficient and unpredictable Daladalas on the main 
corridors. DART will be implemented in six phases, with the construction of the first phase in 2010. Once the current plans are implemented, the total corridor length will be more than 130 kilometers, with a long-term plan of covering the whole city by the year 2035. The DART Agency will be the public regulatory authority managing the DART system to ensure quality control and will be responsible for policy-setting, regulation, planning, and controlling of operations and marketing of the system (JICA 2007). The DART project seeks to provide a high-quality, affordable mobility service that improves both the environment and the quality of life of the city's residents.

Although the BRT is aimed to enhance and improve the quality of service to regain passenger confidence in public transport, the critical challenge remains regulating and controlling cost minimization pressure of the profit-seeking private sector, which currently dominates public transport service provision, without sacrificing the quality of service offered (Sohail et al. 2004). The main objective of this paper is to analyze commuter preferences towards the proposed BRT system in Dar-esSalaam and explore user perceptions of its service quality attributes.

\section{Overview of Earlier Studies and Approaches}

The need to improve the quality of public transit services to meet the everincreasing needs and expectations of passengers has been one of the main desires of urban transport planners worldwide (Mfinanga and Ochieng 2006; Ji and Gao 2010; Currie and Delbosc 2011). For each individual journey, people have the choice between different travel modes, each with specific characteristics, advantages, and disadvantages (Garling 2005). In other words, public transport competes with other modes and will be used only if it can meet the expectations of the traveling public, that is, if it can deliver an attractive, accessible, reliable, affordable, and safer service (Stradling et al. 2007; Currie, 2005). A thorough understanding of user perceptions of the quality of service provided by the system is, therefore, a prerequisite to realization of the above ambition.

A review of the international literature on public transit quality shows that quality of service in public transit reflects passenger perception of transit performance (Currie and Wallis 2008; Hensher et al. 2003). The concept of service quality has been extensively applied to public transit systems and may be defined as customer perception of how well a service meets or exceeds their expectations (Geetika and Nandan 2010). Service quality can be measured in terms of customer percep- 
tion, customer expectation, customer satisfaction, and customer attitude. It covers many diverse topics, such as comfort outside and inside the vehicle, journey times, convenience of service, and existence of supporting infrastructure (Litman 2008; Currie 2005). The overall process to improve public transit service quality entails identification of customer priorities and needs, measurement of customer satisfaction using appropriate indices, use of this feedback to evaluate relevant service parameters, and, finally, the definition and implementation of measures to improve the services provided to customers. Research has revealed that the quality of each of the public transit service attributes is related to the importance each individual commuter places on it (Dell'Olio et al. 2010; Foote et al. 2001).

Much effort has been made by various studies on urban public transit services; for example, a number of approaches and techniques such as customer loyalty and benchmarks have been used to define, assess, and evaluate quality of service. These approaches have been addressed at different levels of significance in various countries, primarily in the developed world (Foote et al. 2001; Morpace International, Inc. 1999; Kittelson \& Associates et al. 2003). Some studies have focused on the assessment of public transport level of service (Mfinanga and Ochieng 2006; Too and Earl 2010), while others evaluate public transit service quality from the perspective of user satisfaction. For example Ji and Gao (2010) identified significant factors of satisfaction from the analysis of people's satisfaction with public transportation as well as accessibility factors and personal attributes with a multi-level logistic regression model. Dell'Olio et al. (2010) used ordered probit models to evaluate how bus users perceive the quality of their public transit service. Stradling (2007) characterized the dimensions of bus service acceptability by examining what bus users disliked and liked about traveling by bus in Edinburgh using factor analysis. Tyrinopoulos and Antoniou (2008) combined factor analysis and ordered logit modeling to assess the quality implications of the variability of user perceived satisfaction across public transit systems. Too and Earl (2010) developed and used a SERVQUAL framework to measure public transport services. Their findings revealed a wide gap between community expectations of public transport services and the actual service quality provided. Eboli and Mazzulla (2008) conducted a stated preference experiment to identify the importance of service quality attributes on global customer satisfaction and calculated a service quality index that provides an operationally-appealing measure of current or potential service effectiveness. 
Although there is much work on public transit quality, based on the authors' knowledge, the study of this topic in Sub-Sahara African cities, and Dar-es-Salaam in particular, using a similar approach is very rare, indeed perhaps not available at all. Knowledge of how people value the quality of a public transit service would benefit transport planners, policy makers, and public transit operators to stipulate strategies of service quality improvement. This would help to design service quality interventions that meet customer expectations while eliminating subjectivity in the decision making of urban policies. This paper aims to address this gap in knowledge and reports the results of a stated preference survey conducted in the city of Dar-es-Salaam.

\section{Methods and Materials}

\section{Survey Design and Data Collection Procedure}

A stated preference (SP) survey was conducted in September 2007 among individual regular commuters in the city of Dar-es-Salaam who traveled to the CBD for main daily activities. ${ }^{1}$ The objective of the survey was to collect stated choice data to analyze commuter preferences towards the proposed BRT quality of service. Given that the BRT system was not yet in place at the time of the survey, the study was conducted to only daily commuters who were assumed to be an appropriate target group with the potential of using and affording the BRT system service.

The survey samples were collected from pre-selected zones of the city based on three criteria: 1) whether the residential zones are densely populated and located in areas around the proposed BRT corridors, 2) whether the residential zones are planned or unplanned, in order to capture views from different categories of people, and 3) the residential zone location distance from the CBD. Based on these criteria, the selection of the survey zones was done with assistance from group discussions held with local experts from DART, the Dar-es-Salaam City Council, Ardhi University, the University of Dar-es-Salaam, and the JICA team that was conducting the city transport master plan study. Individuals were approached in their homes (within the pre-selected zones) in the evenings after they had returned from their daily activities. This was done purposely to allow for more time for the respondents to develop their answers in a relaxed atmosphere for the choice questions. The homes were visited randomly with the help of local leaders in a given residential area. The study employed the concentric zonal survey approach, which is sampling respondents in reference to distance from CBD (Goudie 2002). A CBD is a major trip attraction zone of a city and, for the case of Dar-es-Salaam, the CBD accom- 
modates most of the public and private activities and is a major destination of most of the commuting trips in the city. The city was divided into four ring buffers based on the radial distance from $C B D$, with the $C B D$ as a reference point. The four ring buffers created were zones within $5 \mathrm{~km}$ from the $C B D$, zones $5-10 \mathrm{~km}$ from the $C B D$, zones $10-15 \mathrm{~km}$ from the $C B D$, and zones beyond $15 \mathrm{~km}$ from the CBD. It was decided to work with categories of commuters (potential users) defined by radial distance from the $C B D$ with an aim to reveal whether the residential location distance from the CBD has an influence on the commuter choice of the proposed BRT service.

The survey questionnaire used was composed of three main parts. The first part collected information related to individual travel behavior, which was used to customize the second part and gave an overview of the sample travel characteristics. The second part was strictly stated choice questions (i.e., a series of binary bus choices). The third part was meant to collect socio-economic and demographic information of the sample. A total of 740 commuter respondents were interviewed from different residential zones within the four different ring buffers, resulting in 684 completed questionnaires, a response rate of 92 percent. The high response rate is attributed to the methods employed and the mini-pilot survey done prior the main survey data collection. As each respondent made nine choices from the nine scenarios, the potential total number of observations (pseudo-individuals) was 6,156 , a reasonable sample size for choice modeling. Earlier studies show that the ideal number of respondents required per design treatment is between 30 and 50 individuals (Ahern and Tapley 2008; Hensher 1994). Normally, 500 to 1,000 sample observations are more than adequate to give better estimations (Louviere et al. 2000). Because of the focus on commuters, the respondents interviewed were ages 15 years and above.

\section{Stated Choice Design}

The SP approach has been widely used in transportation, given its potential to measure how people choose not-yet-existing travel modes or how people take actions in case of introducing new policies-for example, in this case with the introduction of a new bus transit system (Hensher 1994). As people in Dar-esSalaam have not experienced the proposed BRT system, it is not reliable to use only data about actual travel behavior to represent people's future preferences; it is necessary to use a stated preference approach, which has the ability to measure responses under not-yet-existing conditions (Louviere et al. 2000). SP questions were designed to reveal the alternatives that individual commuters say they would 
choose in a given hypothetical situation. Each alternative is assigned a certain combination of attributes, and the individual chooses the alternative he/she finds has the most appealing combination of attributes.

\section{Definition of the BRT Attribute Variables}

The attributes used in the choice experiment are based on the proposed BRT service quality features obtained from the BRT system design reports of Logit (2007) from DART and the Dar-es-Salaam City Council. The three attributes were travel time, travel fare, and comfort. Travel time (one way) in this study is defined as the sum of access (walking) time to BRT stop, waiting time at BRT stop, and in-bus travel time taken to reach the CBD. Travel fare (one way) is defined as a fee charge of using the BRT to reach the CBD. DART will operate according to a flat fare system and, thus, respondents were presented the same travel fare. According to the BRT Investors documents, the travel fare for the BRT one way would be 500 Tshs, and this was the fare considered in this study. Comfort in this study was defined as the in-bus comfort during the trip to CBD. The comfort attribute was measured at three levels: 1) comfortable seating-the commuter can sit during the complete journey; 2) comfortable standing-the commuter can only stand during the trip but the standing conditions are considered comfortable if the commuter can easily move his arms and legs and can easily leave the bus without the need to ask other people to give space; and 3) overcrowded standing - the commuter has no seat available during the trip but, in this case, the standing conditions are worse than comfortable standing; walking through the bus is almost impossible, and, thus, the respondent can roughly make a comparison with the situation of an overcrowded Daladala.

The three attributes were selected among others based on input obtained through work sessions with local experts from DART, the Dar-es-Salaam City Council, and Ardhi University, which also helped to individualize the most relevant attribute levels. Comfort was also considered in this study because other studies in Dar-esSalaam have shown that people value comfort highly (Kanyama et al. 2004). The attributes and their levels were later validated based on input from a mini-pilot survey among daily commuters. Hensher et al. (2005) suggests that three attributes with three levels are enough to provide knowledge of a good approximation of the true underlying utility function. The attributes were varied over three levels. Table 1 describes the BRT attribute variables used in the study. 


\section{Table 1. Description of BRT Attribute Variables}

\begin{tabular}{|c|c|c|c|}
\hline Attribute & Level values & Unit & Description \\
\hline Travel time & $\begin{array}{l}0-5 \mathrm{~km}: 15,30,45 \\
5-10 \mathrm{~km}: 20,40,60 \\
10-15 \mathrm{~km}: 30,55,80 \\
>15 \mathrm{~km}: 45,75,105\end{array}$ & Minutes & $\begin{array}{l}\text { Total BRT travel time to CBD (walk time } \\
\text { to BRT stop + wait time at BRT stop + } \\
\text { in-vehicle travel time) (one way) }\end{array}$ \\
\hline Travel fare & $300,500,700$ & Tshs* & Total BRT travel fare to CBD (one way) \\
\hline Comfort & $\begin{array}{l}1=\text { seat guaranteed } \\
0=\text { comfortable standing } \\
-1=\text { overcrowded standing }\end{array}$ & $\begin{array}{l}\text { Level of } \\
\text { comfort }\end{array}$ & Comfort level when inside the bus \\
\hline
\end{tabular}

${ }^{*}$ Tshs = Tanzania Shillings, 1 US\$ = approx. 1,200 Tshs as of September 2007

For the attribute level values to be realistic for the study context and acceptable to respondents, the maximum and minimum attribute level values for the experiment were set close to the attribute level values of a Daladala and realistic for the BRT system. The attribute levels were tested through a pilot survey with 20 individual Daladala regular commuters. This enabled us to increase the realism of the hypothetical choice context to a plausible maximum by bridging the gap between reality and stated intentions. The pilot survey also enabled us to validate the questionnaire and verify the existence of trade-offs in the evaluation of attributes and the lack of dominant or lexicographic behavior among respondents.

The stated preference scenarios for this survey were constructed using a fractional factorial design. To produce a fractional factorial, traditional orthogonal design ${ }^{2}$ in statistical package, SPSS was used. The method of producing factorial design in SPSS is described in Hensher et al. (2005). The full factorial allowing estimating main effects requires defining 27 choice scenarios. However, submitting respondents to such a burden runs the risk of losing their attention and obtaining inconsistent answers (Iragüen and de Dios Ortúzar 2004). For these reasons, a fractional factorial was used to reduce the number of scenarios from 27 to 9 .

For the purpose of this study, respondents were asked to choose between two unlabeled $^{3}$ bus alternatives-Bus A or Bus B. Unlabeled choice scenarios were presented to respondents to avoid bias that could be brought by the attached label "BRT" when making a choice. In Dar-es-Salaam, where most people have a low literacy level, it was necessary to present choice scenarios in a way that could be interpreted easily and homogeneously to achieve better utility estimations. Carson et al. (1994) recommended the use of graphic representations as an aid for respondents, and this was emphasized in recent SP studies (Iragüen and de Dios Ortúzar 2004; Tilahun et al. 2007). To make sure that every individual respondent interprets 
homogeneously the same bus quality attributes in all choice scenarios, especially for the qualitative attributes such as comfort, where different interpretations from respondents were possible, a combined pictorial and verbal format was presented and elaborately tested at the SP exercise. Figure 1 is an example of one of the nine stated preference scenarios presented in the survey. (A copy of the nine SP survey choice sets can be available from the author upon request.)

Ni basi gani unapendelea? (1/9)

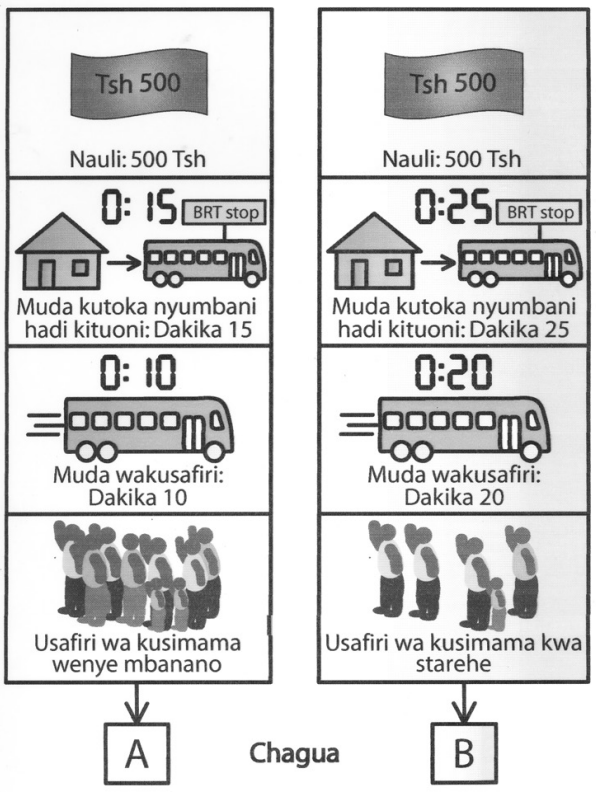

Figure 1. Sample stated preference scenario

\section{Model Structure and Explanatory Variable Specification}

The stated choice data from the SP survey was analyzed using a random utility model. This is, by far, the most-used model for processing data from choice experiments in transportation research (Ben-Akiva and Lerman 1985; Louviere et al. 2000). The model assumes that travel decision makers face a utility maximization problem based on the cost and quality of service stemming from using a given mode and the uncertainty of choosing the given mode (Ortúzar and Willumsen 1994). This study uses a random utility model in the form of binary logit. The maximum likelihood method was used to estimate the binary logit models. The stated choice data was modeled using Bierlaire's optimization toolbox for general 
extreme value model estimation (BIOGEME) version 1.5 (Bierlaire 2003). The specified random utility model estimated for this study is expressed as:

$$
U_{b n}=V_{b n}+\varepsilon_{b n}
$$

Where, $n$ is an index for individuals; $b$ is an index for bus (BRT) - ( $b=$ A or B, because each scenario comprises two alternative buses); $U_{b n}=$ the utility of the bus rapid transit (BRT/DART) by an individual $n ; V_{b n}=$ the systematic utility component of the BRT; and the random error term $\varepsilon_{b n}=$ the non-observable utility component of the BRT, which is assumed to be identically and independently standard Gumbel distributed across alternatives and observations. The systematic part of utility depends on the attributes considered in the study and, in this case, is given by the equation

$$
V_{b n}=\sum \beta_{b k} X_{b k n}
$$

Where, $V_{b n}=$ the systematic utility component of the BRT; $\beta_{b k}=$ the utility coefficient associated with attribute $X_{b k n}$ of the BRT; $X_{b k n}=$ represents a vector of explanatory variables specific to BRT $b$ and individual $n$; and $k=$ the $k^{\text {th }}$ attribute of the BRT. The systematic utility functions of the alternatives are linear combinations of the bus service quality attributes, as shown in the following expression:

$$
V_{b r t \_b}=\beta_{t t_{-} b_{i}} T T_{\text {brt }}+\beta_{\text {fare } \_b_{i}} F A R E_{b r t}+\beta_{c f t \_b} C F T_{b r t}
$$

Where, $V_{\text {brt } \_b_{i}}=$ systematic utility component of BRT per buffer ring; $T T_{\text {brt }}=$ total travel time of BRT (one way); $F A R E_{b r t}=$ total travel fare of BRT (One way); $C F T_{b r t}=$ comfort of the BRT; $\beta_{t t \_} b_{i}=$ coefficient associated with attribute travel time, specific for each buffer ring; $\beta_{\text {fare } b_{i}}=$ coefficient associated with attribute travel fare, specific for each buffer ring; $\beta_{c f t \_} b_{i}=$ coefficient associated with attribute comfort, specific for each buffer ring; and $b_{i}=$ buffer ring where $=0-5 \mathrm{~km} ; 5-10 \mathrm{~km}$; $10-15 \mathrm{~km}$; and $>15 \mathrm{~km}$.

As this was an unlabeled design, the intercept has not been considered when designing the models, and no socio-economic variables have been introduced (Hensher et al. 2005). For a more detailed discussion on stated preference surveys, see Polak and Jones 1997; Rose and Bliemer 2009; Rose et al. 2008; and Hensher et al. 2005. For more detailed discussion on discrete choice modeling, see Ben-Akiva and Lerman 1985; Louviere et al. 2000; and Ortúzar and Willumsen, 1994. 


\section{Results and Discussion}

\section{Descriptive Statistical Analysis}

The descriptive analysis results of the survey data (see Table 2) show relatively good representation of male and female respondents, and the comparison between the sampled population and the Dar-es-Salaam population indicates a relatively good representative sample. The employment status of the sampled population shows that all groups were represented. However, the self-employed are over-represented because, unlike the city population at large, most commuters to downtown are self-employed businessmen and petty traders.

Table 2. Socio-Demographic Profile of Sample Respondents

\begin{tabular}{|c|c|c|}
\hline Factor & \% Sample Respondents & $\begin{array}{c}\text { \% Dar-es-Salaam } \\
\text { Population }\end{array}$ \\
\hline \multicolumn{3}{|l|}{ Gender* } \\
\hline Male & 53.7 & 50.5 \\
\hline Female & 46.3 & 49.6 \\
\hline \multicolumn{3}{|l|}{ Age Group* } \\
\hline $15-25$ years & 30.3 & 36.5 \\
\hline $26-64$ years & 68.1 & 60.4 \\
\hline$>64$ years & 1.6 & 3.1 \\
\hline \multicolumn{3}{|c|}{ Employment Status** } \\
\hline Full-time & 21.2 & 22.1 \\
\hline Part-time & 12.9 & $\mathrm{~N} / \mathrm{A}$ \\
\hline Self-employed & 44.7 & 22.8 \\
\hline Student & 11.8 & 11.5 \\
\hline Other & 9.4 & \\
\hline \multicolumn{3}{|l|}{ Education Level ${ }^{* *}$} \\
\hline No education & 1.3 & 7.6 \\
\hline Primary & 32.3 & 60.6 \\
\hline Secondary school & 44.9 & 1.7 \\
\hline Higher & 21.2 & 2.9 \\
\hline Missing data & 0.3 & \\
\hline
\end{tabular}

*Source: Population \& Housing Census 2002

** Source: Source: Household Budget Survey 2000/01

Most respondents were between 26 and 64 years of age, as expected, since this is the working-age group, which indicates good data in the point of view of this 
research. A higher percentage of the sampled respondents had completed their secondary-level education compared to the city population. This difference is reasonable since one would expect daily commuters to have a higher education level.

Table 3 shows that most commuters travel to CBD for business (large-scale business, petty trading, business shopping) activities. Those who travel to the CBD for office work activities i.e., government and private institutions, constitute about 29 percent, school trips about 10 percent, and remaining others 13 percent. The modal share of the sample shows that 88 percent of commuters use public transport (Daladala), 8.9 percent private car, 1.8 percent walk, 0.3 percent bicycle, and 1.1 percent other modes.

Table 3. Travel Behavior of Sample Respondents

\begin{tabular}{|c|c|c|}
\hline Factor & \% Sample Respondents & $\begin{array}{c}\text { \% Dar-es-Salaam } \\
\text { Population }\end{array}$ \\
\hline \multicolumn{3}{|l|}{ Main trip purpose to $C B D$} \\
\hline Work & 28.5 & N/A \\
\hline School & 9.5 & N/A \\
\hline Business & 49.0 & N/A \\
\hline Other & 12.9 & N/A \\
\hline Missing data & 0.1 & N/A \\
\hline \multicolumn{3}{|l|}{ Main mode of travel } \\
\hline Daladala (public transport) & 87.9 & $42.0^{*}$ \\
\hline Bicycle & 0.3 & $3.0^{*}$ \\
\hline Walking & 1.8 & $46.0^{*}$ \\
\hline Private car & 8.9 & $9.0^{*}$ \\
\hline Other & 1.1 & N/A \\
\hline
\end{tabular}

* Source: Amer et al. 2007

$\mathrm{N} / \mathrm{A}=$ data not available

\section{Model Results}

Results from all models have shown that the parameter on travel time variable is negative and highly significant, reflecting a preference for shorter travel times. The parameter on the travel fare variable is negative and shows a significant aversion to expensive travel fares. The comfort parameter has a positive sign, as expected, and significantly indicates that commuters prefer traveling in a comfortable environment. 
To examine the relative importance of the attributes, willingness to pay (WTP) values were estimated. These estimates examine the value attached to each of the attributes by respondents in different locations of the city. The WTP value for travel time attribute of the BRT is the marginal rate of substitution between travel time and travel fare and is given by the ratio of the travel time utility parameter and the travel fare utility parameter. Likewise, the WTP value for comfort is given by the ratio of comfort utility parameter and the fare utility parameter (Louviere et al. 2000). The results shown in Table 4 suggest that a sampled individual is willing to pay, on average, 30.2 Tshs to save 1 minute of time spent traveling to the CBD, holding other factors constant. In the same way, a sampled individual is willing to pay 343 Tshs to gain a unit level of in-bus comfort. The results again show that, on average, a sampled individual is willing to pay 11.4 times more to gain a unit level of in-bus comfort than to save a unit of travel time.

Table 4. Overall Model Based on Total Sample

\begin{tabular}{|l|c|c|c|c|}
\cline { 2 - 5 } \multicolumn{1}{c|}{} & \multicolumn{4}{c|}{ City Level } \\
\hline Attribute & Coef. & WTP & t - test & p - value \\
\hline Travel Time & -0.0487 & 30.2 & -17.75 & .000 \\
\hline Travel Fare & -0.00161 & & -5.16 & .000 \\
\hline Comfort & 0.552 & 343 & 10.38 & .000 \\
\hline No. of estimated parameters & 3 & & & \\
\hline No. of observations & 6,156 & & & \\
\hline Init. log-likelihood & -4266.321 & & & \\
\hline Final log-likelihood & -2652.603 & & & \\
\hline Likelihood ratio test & 3227.436 & & & \\
\hline Rho-square & 0.378 & & & \\
\hline
\end{tabular}

Tables 5 and 6 show results from models depending on distance from CBD. A sampled individual is willing to pay, on average, 18.3 Tshs, 4.2 Tshs, 5.5 Tshs, and 8.6 Tshs to save 1 minute of time spent traveling to the CBD ceteris paribus when from within $5 \mathrm{~km}, 10 \mathrm{~km}, 15 \mathrm{~km}$, and beyond $15 \mathrm{~km}$ distance from the $C B D$, respectively. Likewise, on average, holding other factors constant, a sampled individual is willing to pay 745 Tshs, 360 Tshs, 291Tshs, and 282 Tshs to gain 1 unit level of comfort from within $5 \mathrm{~km}, 10 \mathrm{~km}, 15 \mathrm{~km}$, and beyond $15 \mathrm{~km}$ distance from the $C B D$, respectively. The results also reveal that a sampled individual is willing to pay, on average, 40.7, 86, 52.9, and 33 times more to gain 1 unit level of comfort than to save 1 unit of travel time when from within $5 \mathrm{~km}, 10 \mathrm{~km}, 15 \mathrm{~km}$, and beyond $15 \mathrm{~km}$ distance from 
the $C B D$, respectively. The model results, in all cases, clearly indicate that the value attached to comfort (in-bus during travel) is higher than that of travel time, simply suggesting that an individual commuter would be willing to pay more to gain a unit level of comfort (in-bus) than to save a unit of travel time holding other factors constant. For example, considering the overall model results (Table 4), an individual commuter from any zone in the study area is willing to pay, on average, 11.4 times more to gain a unit level of comfort than to save a unit of travel time.

Table 5. Models Depending on Radial Distance from CBD

\begin{tabular}{|l|c|c|c|c|c|c|c|c|}
\cline { 2 - 10 } \multicolumn{1}{c|}{} & \multicolumn{4}{c|}{$<5$ km } & \multicolumn{5}{c|}{$5-10 \mathbf{~ k m}$} \\
\hline Attribute & Coef. & WTP & t - test & $\mathbf{p}$ - value & Coef. & WTP & t - test & p - value \\
\hline Travel Time & -0.0272 & 18.3 & 3.23 & .000 & -0.0148 & 4.2 & -2.81 & .010 \\
\hline Travel Fare & -0.00149 & & -2.01 & .040 & -0.00353 & & -5.26 & .000 \\
\hline Comfort & 1.11 & 745 & 8.26 & .000 & 1.27 & 360 & 10.96 & .000 \\
\hline $\begin{array}{l}\text { No. of estimated } \\
\text { parameters }\end{array}$ & 3 & & & & 3 & & & \\
\hline No. of observations & 610 & & & & 1,341 & & & \\
\hline Init. log-likelihood & -422.127 & & & & -923.272 & & & \\
\hline Final log-likelihood & -352.817 & & & & -799.266 & & & \\
\hline Likelihood ratio test & 138.618 & & & & 248.012 & & & \\
\hline Rho-square & 0.164 & & & & 0.134 & & & \\
\hline
\end{tabular}

Table 6. Models Depending on Radial Distance from CBD

\begin{tabular}{|l|c|c|c|c|c|c|c|c|}
\cline { 2 - 10 } \multicolumn{1}{c|}{} & \multicolumn{4}{c|}{$10-15 \mathbf{~ k m}$} & \multicolumn{5}{c|}{$>\mathbf{~ k m}$} \\
\hline Attribute & Coef. & WTP & $\mathbf{t}$ - test & $\mathbf{p}$ - value & Coef. & WTP & $\mathbf{t}$ - test & $\mathbf{p}$ - value \\
\hline Travel Time & -0.0343 & 5.5 & -3.06 & .000 & -0.0347 & 8.6 & -6.66 & .000 \\
\hline Travel Fare & -0.00623 & & -3.40 & .000 & -0.00405 & & -4.17 & .000 \\
\hline Comfort & 1.81 & 291 & 5.66 & .000 & 1.14 & 282 & 5.60 & .000 \\
\hline $\begin{array}{l}\text { No. of estimated } \\
\text { parameters }\end{array}$ & 3 & & & & 3 & & & \\
\hline No. of observations & 272 & & & & 504 & & & \\
\hline Init. log-likelihood & -188.536 & & & & -349.346 & & & \\
\hline Final log-likelihood & -153.549 & & & & -302.459 & & & \\
\hline Likelihood ratio test & 69.975 & & & & 93.774 & & & \\
\hline Rho-Square & 0.186 & & & & 0.134 & & & \\
\hline
\end{tabular}


While the willingness to pay values of the attributes differed in the different models, results from all models show that comfort is more valued than travel time and travel fare, revealing its importance to the proposed BRT service quality. Although comfort is more valued than travel time and travel fare from all model results, the value placed on comfort decreased as residential location distance from the CBD increased. People located in zones close to the CBD attach more value to comfort, and this value decreases as one moves away from the CBD. The possible explanation for this may be that people who mainly live in the city peripherals are the poor and, for these people, comfort would be reasonably less valued compared to those who live closer to CBD. Similarly, comfort and travel time are valued higher by commuters from zones close to $\mathrm{CBD}$ (i.e., within $5 \mathrm{~km}$ to the $\mathrm{CBD}$ ) than those from city peripherals. It was, however, expected that commuters from zones located far from the CBD would highly value travel time and comfort since they have to travel longer. The reason could be that people who live close to the CBD are mainly government workers who are highly-educated and business men who have relatively high incomes and, from their point of view, value time as money and comfort as high-class.

On the other hand, although travel fare proved very significant, it was unexpectedly less valued than other attributes. It was, however, expected that people would value travel fare more than comfort and travel time given that the Dar-es-Salaam population is mainly low income. There are two possible explanations: 1) since most commuters usually have to make one or more Daladala transfers currently from their residential locations to reach the $\mathrm{CBD}$ and each time a transfer is made the travel fare doubles (the Daladala fare ranged from 250 to 500 Tshs for one-way travel at the time of the survey), the BRT travel fare (expected to charge a flat fare of 500 Tshs one way) may be seen less expensive to commuters than the Daladala fare charge; 2) given the poor service and traveling environment of the Daladalas, characterized by uncomfortable, unsafe, and overcrowded conditions, a high preference for comfort over travel fare seems reasonable and unsurprising.

\section{Policy Implications}

The study results indicate that when asked to rank the importance of three variables related to future BRT, commuters in Dar-es-Salaam overall placed a premium on comfort followed by faster travel times and lower fares. There was some variation based on how far the respondents lived from the CBD. Respondents who lived closest to the CBD placed a premium on comfort (in-bus), while respondents who lived on the periphery of the CBD placed a premium on lower fares. 
Moreover, it was possible to extract spatial variation in preferences for the proposed BRT service attributes among the potential users. Such an understanding can be incorporated into the planning process to help planners to make better recommendations and operators to make appropriate investment decisions in order to provide a public transit service that is more appealing to the public.

The high significance of the in-bus comfort, travel time and travel fare attributes in modal choice decision making of a commuter suggests that the DART Agency would pay more attention and consider these attributes important when providing the BRT service. However, when implementing the BRT, priority and particular attention should be given to the order of importance of the attributes for effective delivery of high-quality public transit service.

Although results have generally shown that the travel fare attribute is less important compared to comfort and travel time, planners and decision makers should handle it carefully given its high significance and also given that Dar-es-Salaam's population is dominated by low-income earners. Only through providing transport services characterized by better comfort, lower travel times, and lower travel fares will the proposed BRT be sustainable and attractive to its potential users.

\section{Conclusion}

This study attempted to evaluate the proposed BRT service quality through analysis of commuter stated preferences. In most developing countries, population preferences are hardly taken into account by planners and policy makers, consequently not meeting the desires of the society in question. The stated preference approach and the logit model used in this study can be used to integrate the views of society in planning, especially in evaluating new public transit services or changing existing ones. This gives logit models a very strong policy role by assisting analysts, researchers, and planners in evaluating the impact of many policies as defined by specific mixes of attributes modeled in utility expressions.

A stated preference survey instrument was developed in which people had to make choices among two hypothetical bus alternatives. The results generally revealed that commuters are willing to pay the highest price for traveling in a more comfortable environment, followed by lower travel times and paying lower travel fares. However, the results further highlight the differences in valuation of the attributes based on spatial location of the sampled population in the city. A higher preference is indicated for in-bus comfort by commuters from zones close to the CBD, while 
commuters from the city peripheral zones seemed to have a higher preference for travel fare and appeared less willing to pay for comfort than those from the inner zones of the city. These findings are in line with the statement that people value the characteristics of goods, not the good themselves (Joewono 2009; Walton et al.; 2004). However, Russell (1996) has argued that being willing and able to pay for a commodity does not automatically imply being able to afford it, mainly because the social opportunity cost of the payment may be too high to be socially acceptable.

A methodological conclusion is that the use of pictorial choice cards in the presentation of choice scenarios offers great promise. Not only were all the expected advantages of the approach fully realized, but also the medium was believed to contribute in no little measure to obtaining the choice data and making the exercise more pleasurable to respondents (i.e., less of a burden). The survey instrument contributed to obtaining better responses and a higher response rate than if a different approach had been used. The survey approach is found to be most appropriate and effective to use in cases of hypothetical alternatives, particularly a novel SP survey approach in the context of a developing country with a high proportion of illiterate population.

\section{Acknowledgments}

The authors wish to thank the DART Agency and Dar-es-Salaam City Council for their logistical support and assistance throughout the field work. Insightful comments from Dr. Ir.Thijs Muizelaar are highly appreciated. The support by Ardhi University and input from colleagues Daan Menstrum and Niels Fikse is acknowledged. Further acknowledgment goes to Nuffic (NFP) for provision of funds to conduct the research. Finally, the authors appreciate the two anonymous reviewers for their helpful comments on the previous version of this paper.

\section{Endnotes}

${ }^{1}$ Main daily activities in this study are defined as government/private office work, personal commercial business, and school.

${ }^{2}$ It is important to note that more recent research concluded that D-efficient designs - the designs that minimize the D-error, that is, the elements included in the asymbiotical matrix of expected variance-covariance-produce significantly improved results in terms of statistical or relative efficiency (Rose and Bliemer 2009; Rose et al. 2008). 
${ }^{3}$ Unlabeled experiment is a choice experiment that uses generic titles for the alternatives where respondents make choices solely on the basis of the differences in attribute level values among the presented options (Louviere et al. 2000). This experiment does not attach a label to any of the alternatives.

\section{References}

Ahern, A. A., and Tapley, N. 2008. The use of stated preference techniques to model modal choices on interurban trips in Ireland. Transportation Research Part A: Policy and Practice 42: 15-27.

Amer, S., Ottens, H. F. L. P., and De Jong, T. P. 2007. Towards spatial justice in urban health services planning : A spatial-analytic GIS-based approach using Dar es Salaam, Tanzania, as a case study. Utrecht University.

Ben-Akiva, M., and Lerman, S.R.1985. Discrete Choice Analysis: Theory and Application to Travel Demand. Cambridge, Massachussets: The MIT Press.

Bierlaire, M. 2003. BIOGEME: A free package for the estimation of discrete choice models. Proceedings of the 3rd Swiss Transportation Research Conference.

Carson, R., Louviere, J., Anderson, D.A., Arabie, P., Bunch.D.S., Hensher, D. A., Johnson, R.M., Kuhfeld, W.F., Steinberg, D., Swait, J., Timmermans, H. and Wiley, J.B. 1994. Experimental analysis of choice. Marketing Letters 5:351-368.

Currie, G. 2005. The demand performance of bus rapid transit. Journal of Public Transportation 8: 41-55.

Currie, G., and Delbosc, A. 2011. Understanding bus rapid transit route ridership drivers: An empirical study of Australian BRT systems. Transport Policy 18: 755-764.

Currie, G., and Wallis, I. 2008. Effective ways to grow urban bus markets: A synthesis of evidence. Journal of Transport Geography 16: 419-429.

Dell'olio, L., Ibeas, A., and Cecín, P. 2010. Modelling user perception of bus transit quality. Transport Policy 17: 388-397.

Department for International Development. 1999. Livelihoods of poor people: What contributions can transport make? workshop report. London, UK: DFID. 
Eboli, L., and Mazzulla, G. 2008. A stated preference experiment for measuring service quality in public transport. Transportation Planning and Technology 31: 509-523.

Foote, J., Stuart, G., and Elmore-Yalch, R. 2001. Exploring customer loyalty as a transit performance measure. Transportation Research Record: Journal of the Transportation Research Board 1753:93-101.

Garling, T. 2005. Changes of private car use in response to travel demand management. Traffic and transport psychology: Theory and application. Proceedings of the ICTTP 2004.

Geetika, and Nandan, S. 2010. Determinants of customer satisfaction on service quality: A study of railway platforms in India. Journal of Public Transportation 13: 97-113.

Goudie, D. 2002. Zonal method for urban travel surveys: sustainability and sample distance from the CBD. Journal of Transport Geography 10: 287-301.

Hensher, D., Rose, J. M., and Greene, W. H. 2005. Applied Choice Analysis: A Primer. Cambridge: Cambridge University Press.

Hensher, D. A. 1994. Stated preference analysis of travel choices: The state of practice. Transportation 21: 107-133.

Hensher, D. A., Stopher, P. R., and Bullock, P. 2003. Service quality: Developing a service quality index in the provision of commercial bus contracts. Transportation Research Part A 37: 499-517.

Hine, J. 2003. Social exclusion and transport systems. Transport Policy 10: 263.

Iragüen, P., and De Dios Ortúzar, J. 2004. Willingness-to-pay for reducing fatal accident risk in urban areas: An Internet-based web page stated preference survey. Accident Analysis \& Prevention 36: 513-524.

ITDP 2005. Dar es Salaam: Africa's BRT front runner. Sustainable Transport e-Update, No. 19.

Ji, J., and Gao, X. 2010. Analysis of people's satisfaction with public transportation in Beijing. Habitat International 34: 464-470.

JICA 2007. Dar es Salaam transport policy and system development master plan. Unpublished report, Tokyo: Japanese International Cooperation Agency (JICA). 
Joewono, T. B. 2009. Exploring the willingness and ability to pay for paratransit in Bandung, Indonesia. Journal of Public Transportation 12: 85-103.

Kanyama, C. A., Lindén, A. L., and Lupala, J. 2004. Public transport in Dar-es-Salaam, Tanzania: Institutional challenges and opportunities for a sustainable transport system. Stockholm: FOI/KTH.

Kittelson \& Associates, KFH Group, Parsons Brinckerhoff Quade and Douglas, Inc., and K. Hunter-Zaworski. 2003. Transit Capacity and Quality of Service Manual. Washington, D.C., Transit Cooperative Research Program.

Litman, T. 2008. Valuing transit service quality improvements. Journal of Public Transportation 11: 43-63.

LOGIT. 2007. Project review seminar: Dar es Salaam BRT planning and design final report, DART. Dar es Salaam: Logit Inter-Consult Limited.

Louviere, J. J., Hensher, D. A., and Swait, J. 2000. Stated Choice Methods: Analysis and Application. Cambridge: Cambridge University Press.

Mfinanga, D. A., and Ochieng, M. O.-A. 2006. Development of a model for assessing urban public transport level of service in cities of developing nations. African Journal of Science and Technogy 7: 35-53.

Morpace International, Inc. 1999. A Handbook for Measuring Customer Satisfaction and Service Quality, Washington, D.C., Transit Cooperative Research Program Report 47, National Research Council.

Nkurunziza, A., Zuidgeest, M., and Van Maarseveen, M. 2012. Identifying potential cycling market segments in Dar-es-Salaam, Tanzania. Habitat International 36 (1):78-84.

Olvera, L. D., Plat, D., and Pochet, P. 2003. Transportation conditions and access to services in a context of urban sprawl and deregulation: The case of Dar es Salaam. Transport Policy 10: 287-298.

Ortúzar, J. D., and Willumsen, L. G. 1994. Modelling Transport. Chester, UK: John Wiley \& Sons.

Polak, J., and Jones, P. 1997. Using stated preference methods to examine traveller preferences and responses. In Stopher, P., and Lee-Gosselin, M. (eds.), Understanding Travel Behaviour in an Era of Change. Oxford: Pergamon. 
Rose, J. M., and Bliemer, M. C.J. 2009. Constructing Efficient Stated Choice Experimental Designs. Transport Reviews 29 (5):587-617.

Rose, J. M., Bliemer, M.C.J, Hensher, D.A., and Collins, A.T. 2008. Designing efficient stated choice experiments in the presence of reference alternatives." Transportation Research Part B: Methodological no. 42 (4):395-406.

Russell, S. 1996. Ability to pay for health care: Concepts and evidence. Health Policy and Planning 13: 219-237.

Sohail, M., Maunder, D. A., and Miles, D. W. J. 2004. Managing public transport in developing countries: Stakeholder perspectives in Dar es Salaam and Faisalabad. International Journal of Transport Management 2: 149-160.

Stradling, S., Carreno, M., Rye, T., and Noble, A. 2007. Passenger perceptions and the ideal urban bus journey experience. Transport Policy 14: 283-292.

Tilahun, Y. N., Levinson, M. D., and Krizek, J. K. 2007. Trails, lanes or traffic: Valuing bicycle facilities with an adaptive stated preference survey. Transportation Research Part A 41: 287-301.

Too, L., and Earl, G. 2010. Public transport service quality and sustainable development: A community stakeholder perspective. Sustainable Development 18:51-61.

Tyrinopoulos, Y., and Antoniou, C. 2008. Public transit user satisfaction: Variability and policy implications. Transport Policy 15: 260-272.

Walton, D., Thomas, J. A., and Cenek, P. D. 2004. Self and others' willingness to pay for improvements to the paved road surface. Transportation Research Part A 38: $483-494$.

World Bank 2002. Upgrading low income urban settlements. Country Assessment Report: Tanzania.

World Bank and OECD, 2003. "Urban Transport Services in Sub-Saharan Africa." Sub-Saharan Africa Transport Policy Program, SSATP (Working Paper No.75).

Wright, L. 2002. Bus Rapid Transit: Module 3b. Eschborn: Deutsche Gesellschaft Technische Zusammenarbeit (GTZ).

\section{About the Authors}

Alphonse NkUrunziza (nkurunziza16117@itc.nl) is a Ph.D. candidate in the Department of Urban and Regional Planning and Geo-Information Management, 
ITC, University of Twente, The Netherlands. He is also an assistant lecturer of Transportation Planning and Management in the Department of Civil Engineering at Kigali Institute of Science and Technology (KIST), Rwanda. He holds a B.S. in civil engineering and environmental technology from KIST and an M.S. in urban planning and management with emphasis in transportation planning from ITC, University of Twente. His areas of research interest are in transportation planning, travel demand analysis, travel behavior, urban planning and cycling.

MARK ZUIDGEEST (zuidgeest@itc.nl) graduated as a civil engineer from the University of Twente in The Netherlands and earned his doctorate from the TRAIL Netherlands Research School for Transport, Infrastructure, and Logistics with a dissertation on Sustainable Urban Transport Development in 2005. Currently, he works as assistant professor of Urban Transport in the Department of Urban and Regional Planning and Geo-Information Management (Faculty ITC) and with the Centre for Transport Studies (Faculty CTW) at the University of Twente. His main fields of research and professional interest are sustainable urban transport development and geographical information science for transportation, as well as methods and models for urban transport planning and assessment, primarily in cities in developing countries.

MARK BRUSSEL (brussel@itc.nl) is a lecturer and a researcher in urban infrastructure planning and management in the Department of Urban and Regional Planning and Geo-information Management, faculty of Geo-information Science and Earth Observation, University of Twente. He is a civil engineer by training (Delft University of Technology) and has more than 20 years' experience in the planning, engineering, and construction of urban infrastructure and transport, predominantly in developing countries. In the last 12 years, he has specialized in the application of Geographic Information Science in urban systems. He has developed specific expertise on spatial analytical methods to deal with questions of equitable and sustainable infrastructure and transport provision in urban areas. His main fields of research and professional interests are in public transport and non-motorized transport integration, cycling and climate change, bicycle network design, and GISbased applications in these fields.

MARTIN VAN MAARSEVEen (maarseveen@itc.nl) is a professor of Management of Urban-Regional Dynamics and head of the Department of Urban and Regional Planning and Geo-Information Management, ITC, University of Twente. His main research interests are in urban transport planning, transport policy, urban planning, cycling, and travel demand modeling. 